\title{
Purification and Characterization of Substance P-related Peptide from the Body of the African Lungfish, Protopterus dolloi
}

\author{
Chan-Hee Kim, Eun Jung Kim, Hye-Jin Go, Hyung Ho Lee, Yong-Ki Hong, \\ Hyung-Rak Kim, Joon Ki Chung, Jang-Su Park, ${ }^{+}$Yojiro Muneoka, ${ }^{\ddagger}$ and Nam Gyu Park ${ }^{\star}$ \\ Faculty of Food Science and Biotechnology, Pukyong National University, Busan 608-737, Korea. "E-mail: ngpark@pknu.ackr. \\ ${ }^{\circ}$ Department of Aquatic Life Medicine, Pukyong National University, Busan 608-737, Korea \\ "Department of Chemistry, College of Natural Science, Pusan National University, Busan 609-735, Korea \\ ${ }^{\$}$ Faculty of Integrated Arts and Sciences, Hiroshima University, Higashi, Hiroshima 739-8521, Japan \\ Received April 4, 2006
}

\begin{abstract}
The peptide with structural similarity to mammalian substance $\mathrm{P}(\mathrm{M}-\mathrm{SP})$ has been isolated from extract of the body of the $\Lambda$ frican lungtish, Protopterus dolloi, using the rectum of the newt as the bioassay system. The primary structure of the SP-related peptide was identified as Lys-Pro- $\Lambda$ rg-Pro- $\Lambda$ sp-Gln-Phe-Tyr-Gly-LeuMet-NII $\left(\mathrm{L}-\mathrm{SP}\right.$ ) and contained four substitutions (Lys' $\rightarrow \Lambda \mathrm{rg}, \Lambda \mathrm{rg}^{3} \rightarrow \mathrm{Lys}, \Lambda \mathrm{sp}^{5} \rightarrow \mathrm{Gln}$, and $\mathrm{Tyr}^{8} \rightarrow \mathrm{Phe}$ ) compared with M-\$P; this structure is identical to that of the peptide isolated from the gut of the Australian lungfish. Circular dichroism spectra showed that L-\$P had an unordered structure in the buffer solution and phospholipid bilayers. This peptide was found to have an excitatory effect on rectal muscle tissues of newt, quail, and fish. L-SP also had a more potent vasodilatory effect on the guinea-pig aorta than that of M-SP. The identification of the peptide provides evidence that SP family, hitherto contined to mammals, have a widespread occurrence in lungfish.
\end{abstract}

Key Words : African lungfish, Purification, Substance P

\section{Introduction}

Tachykinins are a family of neuropeptides that possess the carboxy-terminal pentapeptide sequence Phe-X-Gly-LeuMet- $\mathrm{NH}_{2}$, where $\mathrm{X}$ can represent an aromatic (Tyr or Phe) or aliphatic (Ile or Val) amino acid. The conserved C-terminal region of tachykinins is essential for the interaction of the peptides with their receptors, ${ }^{1}$ while the unique N-terminal sequences of the tachykinins provide their receptor-subtype specificity. These peptides are found in various species of invertebrates and vertebrates. ${ }^{2.3}$ The tachykinins so far identified in mammals are substance $\mathrm{P}$ (SP), neurokinin A (NKA), neurokinin $\mathrm{B}(\mathrm{NKB})$, neuropeptide $\mathrm{K}$ and neuropeptide $\gamma$. Tachykinins are widely distributed in the central and peripheral nervous systems and in the endocrine cells of vertebrates. Several studies have suggested that the tachykinins may play a role in various biological activities, including smooth muscle contraction, vasodilatation, glandular and intestinal secretion, neuronal excitation, and immunoregulation. ${ }^{4-6}$

SP-like immunoreactivity occurs in various invertebrates and vertebrates, where it is found in neurons of the brain and gut. ${ }^{4.7}$ Tachykinins which are structurally similar to SP have been isolated from chicken, ${ }^{8}$ lungfish, ${ }^{9}$ and various fish. ${ }^{10-14}$ In particular, members of the SP family which have been found in amphibian include physalaemin, uperolein, and

Abbreviations used: SP, substance P; ACN, acetonitrile; FAB-MASS, fast atom bombardment mass spectrometry; TES. N-[Tris (hydroxymethyl) methyl]-2-aminoethanesulfonic acid; HPLC, high performance liquid chromatography; MS-222, (3-aminobenzoic acid ethylester methanesulfonate salt; TFA, trifluoroacetic acid. kassinin in the frog skin, ${ }^{2}$ ranakinin in frog brain, ${ }^{15}$ ranatachykinin $\mathrm{A}, \mathrm{B}$ and $\mathrm{C}$ in frog brain and intestine, ${ }^{16}$ and bufokinin in toad intestine. ${ }^{17}$

Protopterus dollot is an African lungfish and a member of class Sarcopterygii, which is more closely related to the early amphibians than the modem Neopterygians. Therefore, it seems interesting to identify new bioactive peptides in $P$. dolloi and to compare their structures and actions with those of ordinary fishes and amphibians, which are considered to have evolved from a lungfish-type ancestral animal. In this study, we purified SP- related peptide from the body of the African lungfish, $P$. dolloi; we labeled this peptide as L-SP. Additionally, we report the conformation and biological activities of this peptide.

\section{Experimental Section}

Animals: Adult male and female red-bellied newts (Cvnops pvrrhogaster) were purchased from Hiroshima Experimental Animals (Hiroshima, Japan). Animals were kept in a tank and individual cages, and were fed with commercially-available foods until bioassay. Adult male Japanese quails (Cotumix joponica), aged 3-4 months, were purchased from the Tokai Yuki Company (Toyohashi, Japan). Quails were housed in a temperature-controlled room $\left(25 \pm 2{ }^{\circ} \mathrm{C}\right)$ with a daily 16 -h light and 8 -h dark cycle. Specimens of the African lungfish, $P$. dolloi, of both sexes were used in the present study. The fish were deeply anaesthetized by MS-222, killed by decapitation.

Body tissue extraction: All body tissue, except the heads. skin, fins, and spinal cords, was removed from 30 male and 
female lungfish specimens. The body tissue, except the brains and spinal cords, was frozen in liquid nitrogen, and stored in a deep freezer $\left(-80^{\circ} \mathrm{C}\right)$. Each frozen sample was boiled in $2.5 \mathrm{~L}$ of water for $10 \mathrm{~min}$ and $75 \mathrm{~mL}$ of acetic acid was then added to the boiled materials. The material was homogenized with Multi blender Mill (Nihonseiki Kaisha, Ltd) and centrifuged at $15,000 \times \mathrm{g}$ for $40 \mathrm{~min}$ at $4{ }^{\circ} \mathrm{C}$; the resulting precipitate was homogenized once more and was then extracted. The first and second extracted supernatants were pooled and concentrated to $2.4 \mathrm{~L}$ using a rotary evaporator at $40^{\circ} \mathrm{C}$. A volume of $3.6 \mathrm{~L}$ of ethanol was then added. The solution was centrifuged again as above, and the supernatant was concentrated to $1 \mathrm{~L}$. To this solution, $24 \mathrm{~g}$ of $\mathrm{NaCl}$ and $1 \mathrm{~L}$ of ethanol were added. After centrifugation, the supernatant was concentrated to $500 \mathrm{~mL}$. Next, $50 \mathrm{~mL}$ of $1 \mathrm{~N} \mathrm{HCl}$ was added to the concentrated solution, which was then mixed and centrifuged as described above. The resulting supernatant was forced through eight Sep-Pak C18 cartridges (Waters, Milford, MA, USA). The retained material was eluted in $60 \%$ methanol (RM 60). RM 60 was concentrated by vacuum centrifugation. We used the peptideinduced contraction of the rectums of C. pwrhogaster as a bioassay at each purification step.

Purification of L-SP: In the first step of L-SP purifications, the RM 60 was applied to a reversed-phase HPLC column (ODP-50, Asahipak, $6 \mathrm{~mm} \times 250 \mathrm{~mm}$ ) equilibrated with $0.1 \%$ trifluoroacetic acid (TFA), and was eluted with a linear gradient of $0-60 \%$ acetonitrile $(\mathrm{ACN})$ in $0.1 \%$ TFA $(\mathrm{pH} \mathrm{2.2)} \mathrm{for} 120 \mathrm{~min}$ at a flow rate of $1.0 \mathrm{~mL} / \mathrm{min}$. An aliquot of each fraction was examined by bioassay. Bioactive fractions were concentrated and subjected to cationexchange HPLC (SP-5PW, Tosoh, $7.5 \mathrm{~mm} \times 75 \mathrm{~mm}$ ) with a linear gradient of $0-1.0 \mathrm{M} \mathrm{NaCl}$ in $10 \mathrm{mM}$ phosphate buffer (pH 7.2) for $100 \mathrm{~min}$ at a flow rate of $0.5 \mathrm{~mL} / \mathrm{min}$. The fractions that had been eluted at about $0.2 \mathrm{M} \mathrm{NaCl}$ were again subjected to C-18 reversed-phase HPLC (ODS-80TM, Tosoh, $4.6 \mathrm{~mm} \times 150 \mathrm{~mm}$ ) with a linear gradient of $5-25 \%$ ACN in $0.1 \%$ TFA for $80 \mathrm{~min}$ at a flow rate of $0.5 \mathrm{~mL} / \mathrm{min}$. The bioactive fractions were further rechromatographed by repeating the cation-exchange column (SP-5PW) at the same conditions and reversed-phase column (ODS-80TM) with a linear gradient of $16-26 \% \mathrm{ACN}$ in $0.1 \%$ TFA for $50 \mathrm{~min}$ at a flow rate of $0.5 \mathrm{~mL} / \mathrm{min}$. Bioactive fractions were subsequently subjected to the next HPLC (ODS-80TM) with an isocratic elution of $20 \% \mathrm{ACN}$ in a $0.1 \%$ TFA at a flow rate of $0.5 \mathrm{~mL} / \mathrm{min}$. Finally, the fraction was purified as a single peak on the same column with an isocratic elution of $22 \%$ $\mathrm{ACN}$ in $0.1 \%$ TFA at a flow rate of $0.3 \mathrm{~mL} / \mathrm{min}$ (Fig. 1).

Structure determination: The isolated peptide was subjected to amino acid sequence analysis by automated Edman degradation with a gas-phase sequencer (PSQ-1, Shimadzu, Kyoto, Japan). Molecular weight was determined using fast atom bombardment mass spectrometry (FAB-MS; JEOL JMS-HX 100/110A, Peabody, MA). L-SP was synthesized by standard solid-phase method (PSSM-8, Shimadzu), followed by TFA-anisol cleavage and HPLC purification, as described previously. ${ }^{18}$ Trout SP (T-SP) and Cod SP (C-SP) were also synthesized using the solid-phase method. M-SP was purchased from Sigma (St. Louis, MO, USA). The structures of the synthetic peptides were confirmed by amino acid sequence analysis, FAB-MS analysis, or both. Purified peptide was compared to synthetic L-SP by reversed-phase HPLC (ODS-80TS). The FAB-MS data of the synthetic peptides were as follows: L-SP; base peak, 1350.7, calcd. for, $\mathrm{C}_{62} \mathrm{H}_{95} \mathrm{O}_{15} \mathrm{~N}_{17} \mathrm{~S}_{1}$, 1350.9. T-SP; base peak, 1357.2, calcd. for, $\mathrm{C}_{64} \mathrm{H}_{97} \mathrm{O}_{12} \mathrm{~N}_{19} \mathrm{~S}_{1}$. C-SP; base peak, 1314.3, calcd. for, $\mathrm{C}_{60} \mathrm{H}_{97} \mathrm{O}_{13} \mathrm{~N}_{18} \mathrm{~S}_{1}$.

Bioassay and pharmacology: The activities of both the lungfish-derived, HPLC-fractionated peptides and the synthetic peptides were examined by monitoring the effects of these samples on the spontaneous contraction of the newt rectum. Methods for dissection and recording the tension of the muscle have been described previously. ${ }^{18}$ To assess the activity during the purification process, newt rectums were excised and cut transversely to a 10-20 mm length. Both ends of each excised rectum were tied with two cotton threads. The preparation was then mounted vertically in a recording chamber, with one end connected to the bottom of the chamber and the other end attached to a force-transducer (Type 45196A, NEC-Sanei Instrument Ltd., Tokyo, Japan). The chamber was filled with physiological saline and aerated. The saline was of the following composition $(\mathrm{mM})$ : $\mathrm{NaCl} 110.0, \mathrm{KCl} 2.0, \mathrm{CaCl}_{2} 1.0$, Glucose 10.0 , TRIS $5.0, \mathrm{pH}$ adjusted to 7.4 using $\mathrm{NaOH}$. Output from the force-transducer was monitored by pen recorder (EPR-221A, TOA Electronics Ltd., Tokyo, Japan) via an amplifier (AS1302, NEC-Sanei, Tokyo, Japan) which recorded the mechanical responses of the device. An aliquot of each fraction was evaporated, redissolved in $50 \mu \mathrm{L}$ saline, and added to the chamber. To examine the contraction effects of the synthetic peptide, L-SP, on various vertebrate visceral muscle tissues, black bass (Micropterus sulmoides) and quail (C. japonica) were used along with newt. To record intestinal responses, we utilized a similar bioassay as that described above for the assessment of purification. The composition of the physiological saline used for black bass was the same as that of the saline of the newt. The saline used for the quail was of the following composition (mM): $\mathrm{NaCl} 187.0, \mathrm{KCl} 5.6, \mathrm{CaCl}_{2}$ 2.2, Glucose 11.0, HEPES 10.0, $\mathrm{pH}$ adjusted to 7.4 using $\mathrm{NaOH}$. The guinea-pig (Albino Hartly, 250-330 g) and rat (Wister rat, 230-250 g) were used to investigate the relaxation effects of L-SP on aorta and a mesenteric artery. Aortas of male guinea-pigs and mesenteric arteries of male rats were removed. The arteries were placed in chilled Krebs buffer solution (composition in $\mathrm{mM}: \mathrm{NaCl} 118.7, \mathrm{KCl} 4.7$, $\mathrm{CaCl}_{2} 1.8, \mathrm{KH}_{2} \mathrm{PO}_{4} 1.2, \mathrm{MgSO}_{4} 1.2, \mathrm{NaHCO}_{3} 24.8$ and Glucose $10.1 ; \mathrm{pH} 7.4$ ). The arteries were then freed from adipose and connective tissue under a microscope, and they were then cut into rings ( $2 \mathrm{~mm}$ long). Each ring was mounted on an L-shaped wire attached to a force-displacement transducer (NEC-Sanei, Tokyo, Japan) in a $5 \mathrm{~mL}$ organ bath (US-5, UFER, Kyoto, Japan). The organ bath was maintained at $37^{\circ} \mathrm{C}$ and constantly gassed with a mixture of $95 \% \mathrm{O}_{2}$ and $5 \% \mathrm{CO}_{2}$. 
The arterial rings were allowed to stabilize for $2 \mathrm{~h}$. The resting tension was then adjusted to $1.0 \mathrm{~g}$. The arterial rings were allowed to equilibrate for about $30 \mathrm{~min}$ in nomal medium, during which time the solution was replaced every $10 \mathrm{~min}$. Before the start of experiments, the equilibration was confirmed by $50 \mathrm{mM} \mathrm{K} \mathrm{K}^{+}$-precontraction responses. After the equilibration period, the relaxant responses of prostaglandin $\mathrm{F}_{2 \alpha}\left(\mathrm{I} \times 10^{-5} \mathrm{M}\right)$-contracted rings to the synthetic peptides were measured. Synthetic peptides were cumulatively added to the bath to determine the concentration-response curve of each ring. Relaxation responses to peptides were expressed relative to the contractile response to prostaglandin $\mathrm{F}_{2 \alpha}\left(\mathrm{I} \times 10^{-5} \mathrm{M}\right)$. In this pharmacological experiment, M-SP, T-SP, and C-SP were also used. These peptides were synthesized and their structures were confirmed by sequence analysis and FAB-MS analysis. Each value represents the means \pm S.E., statistical significance was evaluated using Student's t-test for paired data. $\mathrm{ED}_{50}$ value refers to the concentration of a peptide required to give a half of maximal response in the phannacological test.

All bioassay and pharmacological experiments on the muscle tissues of the fish and newt were performed at room temperature, between $22^{\circ} \mathrm{C}$ and $27^{\circ} \mathrm{C}$. The experiments on the muscle tissues of the quail, guinea pig, and rat were performed at $37^{\circ} \mathrm{C}$.

Circular dichroism (CD) spectra: A mixture of uni- and multi-lamellar liposomes was prepared as described previously. ${ }^{19}$ CD spectra were recorded on a JASCO J-600 spectropolarimeter (JASCO, Tokyo, Japan) using a quartz cell of $1 \mathrm{~mm}$ pathlength. Spectra in $5 \mathrm{mM}$ TES buffer $(\mathrm{pH}$ 7.4) containing $0.1 \mathrm{M} \mathrm{NaCl}$ were measured in the peptide concentrations of $100 \mu \mathrm{M}$. For the CD measurements of peptides in phosphatidylcholine from egg yolk (EYPC, Sigma) and a 3:1 mixture of EYPC and phosphatidylglycerol (EYPG, Sigma) liposomes, peptides were dissolved directly in $5 \mathrm{mM}$ TES buffer ( $\mathrm{pH} 7.4$ ) containing $0.9 \mathrm{mM}$ EYPC or EYPC-EYPG $(3: 1)$ liposomes. To compensate for scattering due to liposomes, the CD spectrum of liposomes alone was substracted from that of the peptides in the presence of liposomes. All measurements were performed at $25^{\circ} \mathrm{C}$, and data were expressed in terms of mean residue ellipticity.

\section{Results and Discussion}

As shown in Figure 1, the active substance from the body of $P$. dolloi was finally purified on the $\mathrm{C}-18$ reversed-phase column. Aliquot $(1 / 200)$ of the purified peptide potentiated spontaneous contractions of the isolated rectal preparations of the newt. The determined sequence and detected amounts (picomoles) of each PTH-amino acid in the amino acid sequence analyses was as follows: $\mathrm{Lys}_{41}-\mathrm{PrO}_{46}-\mathrm{Arg}_{29}-\mathrm{PrO}_{43}-$ Asp ${ }_{30}$-Gln ${ }_{36}-\mathrm{Phe}_{35}-\mathrm{Tyr}_{33}$-Gly ${ }_{22}-\mathrm{Leu}_{13}-\mathrm{Met}_{8}$ (L-SP). Molecular ion peaks in the FAB-MS spectra of L-SP was displayed at $1350.7 \mathrm{~m} / \mathrm{z}(\mathrm{M}+\mathrm{H})^{+}$. Based on these results, the structure of L-SP was H-Lys-Pro-Arg-Pro-Asp-Gln-PheTyr-Gly-Leu-Met-NH2. This peptide was thus synthesized,
A

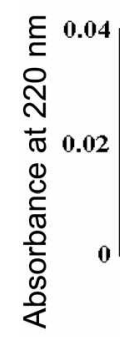

B

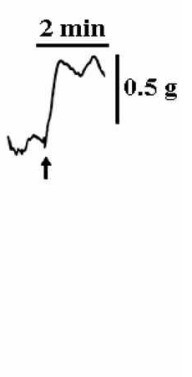

Figure 1. HTLC profile of the final purification procedure of L-SP $(\Lambda)$ and bioactivity of the purified peptide $(B)$. The column (CI8 reversed-phase column, TSKgel ODS-80TM) was cluted with $22 \%$ acetonitrile in $0.1 \%$ TFA ( $\mathrm{pH} 2.2$ ). Fraction of the absorbance peak (indicated by the downward arrow) showed contractile activity on recturn of the newt, Cinops pyrrhogaster.

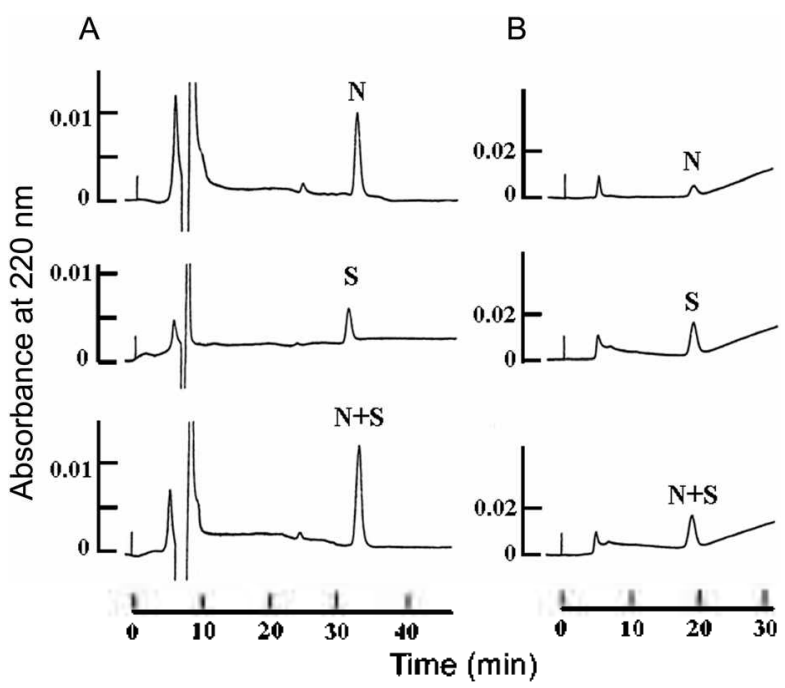

Figure 2. Comparison between HPLC profiles of the native $(N)$ and synthetic (S) L-SP. A: L-SP was injected into C18 reversedphase column (TSKgel ODS-80TM) and cluted with $22 \%$ acctonitrile in $0.1 \% \operatorname{TF} \wedge(\mathrm{pH} 2.2)$. B: L-SP was injected into a cation-exchange column (TSKgel SP-5PW) and eluted with a linear gradient of $0-0.3 \mathrm{M} \mathrm{NaCl}$ in $10 \mathrm{mM}$ phosphate buffer $(\mathrm{pH}$ 7.1) for 30 min. $N+S$, represents a mixture of native and synthetic peptides.

and chemical properties of the synthetic L-SP was compared to that of native peptide. Both the synthetic (S) and native (N) peptides indicated identical behaviors on reversed-phase and cation-exchange HPLC (Fig. 2). The elution profiles of both the native and synthetic L-SP showed the same retention times, and their mixtures were eluted as single absorbance peaks.

Using the synthesized L-SP, we then performed the pharmacological experiments. The L-SP demonstrated contractile activities on the isolated rectums of $C$. pvrhogaster, $C$. japonica and $M$. sulmoides (Fig. 3). Although the threshold concentrations of L-SP were between $10^{-10}$ and $10^{-9} \mathrm{M}, \mathrm{L}-\mathrm{SP}$ may be more sensitive on the rectum of $C$. pwrhogaster than those of $C$. japonica and $M$. sulmoides. We attempted to produce relaxant effects on the guinea-pig 


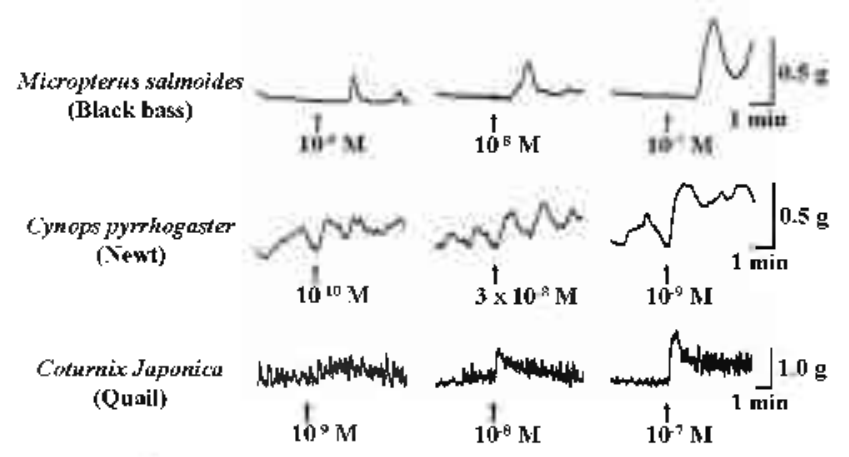

Figure 3. Typical tracings illustrating contractile responses to L-SP on the rectums of black bass, newt, and quail.

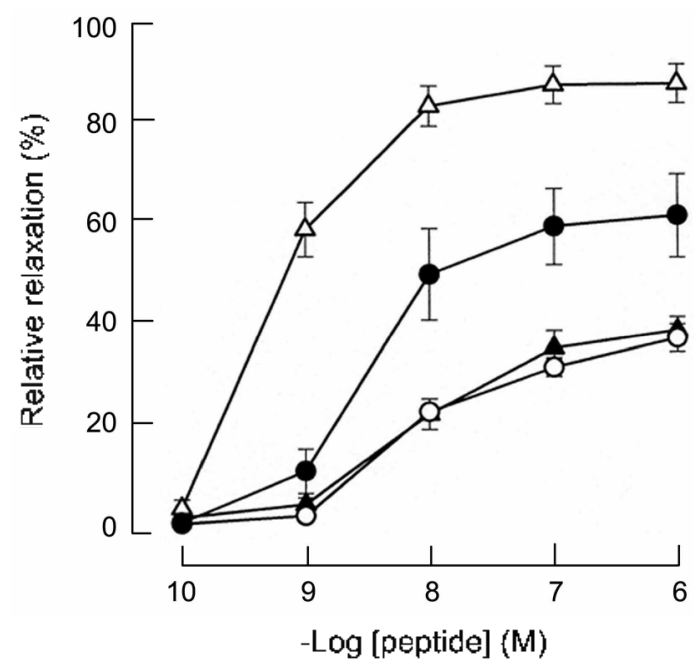

Figure 4. Concentration response curves to $\mathrm{SP}$ induced relaxation $(\mathrm{n}=4)$ in the guinea-pig aorta: L-SP $(\triangle), \mathrm{M}-\mathrm{SP}(\bullet), \mathrm{C}-\mathrm{SP}(\Delta)$ and I-SP ( $C$ ). Relative relaxation was expressed as \% of the maximal response of $\mathrm{PGF}_{2(s,}, \mathrm{I} \times 10^{-5} \mathrm{M}$.

aorta and rat mesenteric artery using the synthetic L-SP, MSP, T-SP. and C-SP that isolated from fish (Fig. 4). All peptides exhibited relaxant activities on the guinea-pig aorta in a dose-dependent manner. L-SP showed more potent relaxant activity than M-SP, T-SP, and C-SP. The potency order in relaxant activities was $\mathrm{L}-\mathrm{SP} \gg \mathrm{M}-\mathrm{SP} \gg \mathrm{T}-\mathrm{SP}=$
Table $1 . \Lambda$ comparison of the primary structures of peptides related to substance $P$ from various vertebrate species

\begin{tabular}{|c|c|c|c|c|c|c|c|c|c|c|c|}
\hline \multirow{2}{*}{$\frac{\text { Peptide }}{\text { Mammals }}$} & \multicolumn{11}{|c|}{ Sequence } \\
\hline & $\mathrm{R}$ & $\mathrm{P}$ & $\mathrm{K}$ & {[} & $Q$ & $Q$ & $\mathrm{~F}$ & $\mathrm{~F}$ & G & $\mathrm{L}$ & M \\
\hline Chicken & - & - & $\mathrm{R}$ & - & - & - & - & - & - & - & - \\
\hline Ranakinin (frog) & $\mathrm{K}$ & - & $\mathrm{N}$ & - & $E$ & $\mathrm{R}$ & - & $\mathrm{Y}^{\prime}$ & - & - & - \\
\hline Bufokinin (canc toad) & $\mathrm{K}$ & - & $\mathrm{R}$ & - & $\mathrm{D}$ & - & - & $\mathrm{Y}$ & - & - & - \\
\hline Lungtish & $\mathrm{K}$ & - & $\mathrm{R}$ & - & $\mathrm{D}$ & - & - & $\mathrm{Y}$ & - & - & - \\
\hline Carp & $\mathrm{K}$ & - & $\mathrm{R}$ & - & $\mathrm{H}$ & - & - & $\mathrm{I}$ & - & - & - \\
\hline $\operatorname{Cod}$ & K & - & $\mathrm{R}$ & - & - & - & - & $\mathrm{I}$ & - & - & - \\
\hline Trout & $\mathrm{K}$ & - & $\mathrm{R}$ & - & $\mathrm{H}$ & - & - & - & - & - & - \\
\hline Sturgeo & $\mathrm{K}$ & - & - & - & $\mathrm{H}$ & - & - & - & - & - & - \\
\hline Dogtisl & $\mathrm{K}$ & - & $\mathrm{R}$ & - & $\mathrm{G}$ & - & - & - & - & - & - \\
\hline
\end{tabular}

C-SP. While I-SP also exhibited relaxant activity on the rat mesenteric artery at $10^{7}$ to $10^{6} \mathrm{M}$, M-SP rarely showed relaxant activity, even at $10^{\circ} \mathrm{M}$ (data nol shown). By measurement of the CD spectra, all four SP-related peptides adopted mainly random structures in buffer solution, neutral and acidic liposomes (Fig. 5).

In spite of the fact that four peptides used in this study adopted similar secondary struclures, we found differences in the induction of relaxant activities. Compared with amino acid sequence in peptides, they possess basic Arg or Lys residues in positions 1 and 3 (I.ys ${ }^{1}$, Arg $^{3}$ in I I-SP, T-SP, and C-SP; Arg ${ }^{1}, \mathbf{L y s}^{3}$ in M-SP); these could be considered interchangeable (Table 1). Hence, for these four tachykinins, important variations occurted only at position 5 (polar residuc) and position 8 (aromatic residue). The greater potency of L,-SP compared to M-SP, T-SP and C.SP indicates that $A s p^{5}$ and/or Tyr are important residues for interaction with the $\mathrm{NK}_{1}$-like receptor. The Asp residuc in L-SP may form a salt bridge with $\mathrm{Lys}^{1}$ (or $\mathrm{Arg}^{3}$ ), as proposed for physalaemin, ${ }^{\text {th }}$ which may stabilize the peptide in a conformation favorable for receptor interaction. In many amphibian tachykinins, possession of a Tyr residue at position 8 appears critical for binding to the amphibian $\mathrm{NK}_{1-}$ like receptors. ${ }^{21}$ Hydrogen bonding might occur between the hydroxyl group of Tyr ${ }^{8}$ and the receptor, whereas such an interaction would not be possible with the Phe ${ }^{x}$ residue of
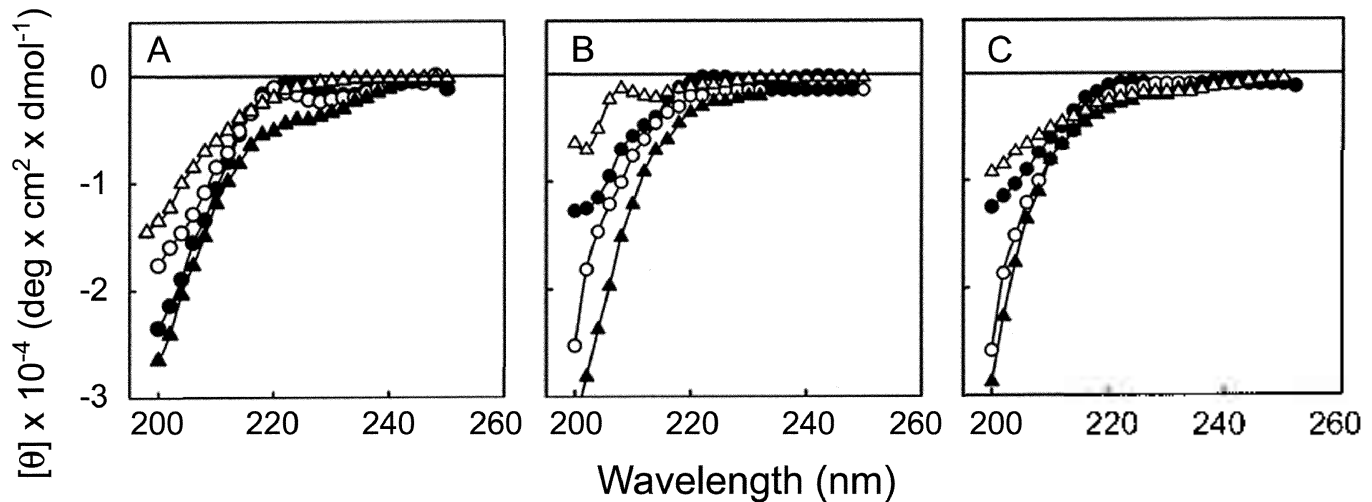

Figure 5. CD spectra of SP-related peptides in TES (A), in the presence of EYPC liposomes (B), and EYPC : EYPG (3: I) liposomes (C). $\mathrm{L}-\mathrm{SP}(\triangle), \mathrm{M}-\mathrm{SP}(\bullet), \mathrm{C}-\mathrm{SP}(\boldsymbol{\Delta})$ and T-SP $(O)$. 
M-SP. For the reason as noted above, L-SP which possesses $\mathrm{Tyr}^{8}$ seems to preferentially interact with the guinea-pig receptor.

The primary structure of L-SP is Lys-Pro-Arg-Pro-AspGln-Phe-Tyr-Gly-Leu-Met-NH $\mathrm{H}_{2}(1350.7 \mathrm{Da})$. This peptide contains four substitutions (Lys' $\rightarrow$ Arg, Arg $^{3} \rightarrow$ Lys, Asp ${ }^{5}$ $\rightarrow \mathrm{Gln}$, and $\mathrm{Tyr}^{8} \rightarrow \mathrm{Phe}$ ) compared to M-SP, and is identical to the peptide isolated from the gut of the Australian lungfish, Neoceratodus forster $i^{9}$ and bufokinin, a SP-related peptide previously isolated from the intestine of the cane toad, Bufo marinus. ${ }^{17} \mathrm{~L}-\mathrm{SP}$ belongs to the SP family, which has members which have been isolated from the both the vertebrate and invertebrate classes. The L-SP presented here, being identical to the SP of Australian lungfish, indicates that the primary structure of L-SP is perfectly conserved in class Sarcopterygii. Based on the results of contractile activity and the homology of the amino acid sequence, the lungfish may be a convergent member which is more closely related to the amphibian than to the teleost on the phylogenetic tree.

The present biological studies suggest that L-SP play important roles in the regulation of gastrointestinal and vascular smooth muscles in lungfish, similar to the roles seen in mammals. Furthermore, identification of this peptide provides evidence that SP families, hitherto confined to mammals, have a widespread occurrence in lungfish.

Acknowledgements. This research was supported by a Korea Sea Grant Program (SGCP-05-09-FA02) of the Ministry of Maritime Affairs \& Fisheries, Republic of Korea.

\section{References}

1. Regoli, D.; Drapeau, G.; Dion, S.; D'Orleans-Juste, P. Pharma- cology $1989,38, \mathrm{l}-15$.

2. Erspamer, V. Trends in Netrosci. 1981, 4, $267-269$.

3. Nässel, D. R. Peptides 1999, 20, 141-158.

4. Otsuka, M.; Yoshioka, K. Physiol. Rev: 1993, 73, 229-308.

5. Harrison, S.; Geppetti, P. Int. J. Biochem. Cell Biol. 2001, $33,555-$ 576.

6. O'Connor, T. M.; O'Connell, J.; O'Brien, D. I.; Goode, T.; Bredin, C. P.; Shanahan, F. J. Cell. Physiol. 2004, 201, 167-180.

7. Holmgren, S.; Fritsche, R.; Karila, P.; Gibbins, I.; Axelsson, M.; Franklin, C.; Grigg, G.; Nilsson, S. Ant. J. Physiol. 1994, 266, R1568-1577.

8. Conlon, J. M.; Katsoulis, S.; Schmidı, W. E.; Thim, L. Regzl. Pept. 1988, 20,171-180.

9. Liu, L.; Conlon, J. M.; Joss, J. M.; Burcher, E. Gen. Comp. Endocrinol. 2002, $125,104-112$.

10. Conlon, J. M.; Deacon, C. F.; O'Toole, L.; Thim, L. FEBS Lett. 1986, 200, $111-116$.

11. Jensen, J.; Conlon, J. M. Ezi: J. Biochem. 1992, 206, 659664 .

12. Waugh, D.; Yunxia, W.; Hazon, N.; Balment, R. J.; Conlon, J. M. Etr. J. Biochem. 1993, 214, 469-474.

13. Waugh, D.; Sower, S.; Bjenning C.; Conlon, J. M. Peptides 1994, 15, 155-161.

14. Waugh, D.; Bondareva, V.; Rusakov, Y.; Bjenning, C.; Nielsen, P. F.; Conlon, J. M. Peptides 1995, 16,615-621.

15. O'Harte, F.; Burcher, E.; Lovas, S.; Smith, D. D.; Vaudry, H.; Conlon, J. M. J. Netrochen. 1991, 57, 2086-2091.

16. Kozawa, H.; Hino, J.; Minamino, N.; Kangawa, K.; Matsuo, H. Biochem. Biophys. Res. Commun, 1991, 177, 588-595.

17. Conlon, J. M.; Wamer, F. J.; Burcher, E. J. Pept, Res. 1988, 5/, 210-215.

18. Fujimoto, M.; Takeshita, K.; Wang. X.; Takabatake, J.; Fujisawa, Y.; Teranishi, H.; Ohtani, M.; Muneoka, Y.; Ohta, S. Biochem. Biophys. Res. Commun. 1998, 242, 436-440.

19. Park, N. G.; Yamalo, Y,; Lee, S.; Sugihara, G Bioploymers 1995. $36,793-801$.

20. Chassaing, G; Convert, O.; Lavielle, S. Biochim. Biophys, Acta $1986,873,397-404$.

21. Severini, C.; Salvadori, S.; Guerrini, R.; Falconieri-Erspamer, G.; Mignogna, G; Erspamer, V. Peptides 2000, 21, 1587-1595. 